\title{
The Role of BTBD9 in Striatum and Restless Legs Syndrome
}

\author{
Shangru Lyu, ${ }^{1}{ }^{\wedge}$ Hong Xing, ${ }^{1}$ Mark P. DeAndrade, ${ }^{1}$ Yuning Liu, ${ }^{1}$ Pablo D. Perez, ${ }^{2}$ Fumiaki Yokoi, ${ }^{1}$ \\ Marcelo Febo, ${ }^{2}$ Arthur S. Walters, ${ }^{3}$ and ${ }^{-O}$ Yuqing Li ${ }^{1}$
}

https://doi.org/10.1523/ENEURO.0277-19.2019

${ }^{1}$ Norman Fixel Institute for Neurological Diseases, Department of Neurology, College of Medicine, University of Florida Gainesville, FL 32610, ${ }^{2}$ Department of Psychiatry, College of Medicine, University of Florida Gainesville, FL 32610, and ${ }^{3}$ Division of Sleep Medicine, Vanderbilt University Medical Center, Nashville, TN

\begin{abstract}
Restless legs syndrome (RLS) is a sensory-motor neurological disorder characterized by uncomfortable sensations in the extremities, generally at night, which is often relieved by movements. Genome-wide association studies (GWAS) have identified mutations in BTBD9 conferring a higher risk of RLS. Knockout of the BTBD9 homolog in mice (Btbd9) and fly results in motor restlessness and sleep disruption. Clinical studies have found RLS patients have structural and functional abnormalities in the striatum; however, whether and how striatal pathology contributes to the pathogenesis of RLS is not known. Here, we used fMRI to map regions of altered synaptic activity in basal ganglia of systematic Btbd9 knock-out (KO) mice. We further dissected striatal circuits using patch-clamp electrophysiological recordings in brain slices. Two different mouse models were generated to test the effect of specific knockout of Btbd9 in either striatal medium spiny neurons (MSNs) or cholinergic interneurons (Chls) using the electrophysiological recording, motor and sensory behavioral tests. We found that Btbd9 KO mice showed enhanced neural activity in the striatum, increased postsynaptic currents in the MSNs, and decreased excitability of the striatal Chls. Knocking out Btbd9 specifically in the striatal MSNs, but not the Chls, led to rest-phase specific motor restlessness, sleep disturbance, and increased thermal sensation in mice, which are consistent with results obtained from the Btbd9 $\mathrm{KO}$ mice. Our data establish the role of Btbd9 in regulating the activity of striatal neurons. Increased activity of the striatal MSNs, possibly through modulation by the striatal Chls, contributes to the pathogenesis of RLS.
\end{abstract}

Key words: BTBD9; cholinergic interneuron; medium spiny neuron; Restless legs syndrome; sleep; striatum

\section{Significance Statement}

Restless legs syndrome (RLS) is a common movement disorder affecting up to $10 \%$ of the population and its pathophysiology is largely unknown. Brain imaging studies have shown striatal involvement. However, whether and how striatal pathology contributes to the pathogenesis of RLS is not known. Polymorphisms in the BTBD9 gene are associated with RLS. Btbd9 complete knock-out (KO) mice have RLS-like phenotypes. With a combination of methods including fMRI, brain slice electrophysiology, cell type-specific KO, and behavioral tests, we demonstrate the importance of the striatum, especially the MSNs, in the pathogenesis of RLS. Our results also suggest a novel mechanism that can explain the effectiveness of dopaminergic drugs for the treatment of RLS patients.

Received July 15, 2019; accepted August 2, 2019; First published August 23, 2019.

The authors declare no competing financial interests.
Author contributions: S.L. and Y. Li designed research; S.L., H.X., M.P.D., Y. Liu, P.D.P., and M.F. performed research; S.L., M.P.D., Y. Liu, P.D.P., M.F., and Y. Li analyzed data; S.L., M.F., A.S.W., and Y. Li wrote the paper; F.Y. and 


\section{Introduction}

Restless legs syndrome (RLS) is a sensorimotor neurologic disease affecting up to $10 \%$ of the general population (Garcia Borreguero et al., 2017). Characteristic symptoms of RLS include an urge for patients to move their legs often accompanied by, or felt to be caused by, uncomfortable sensations in the legs (Lanza and Ferri, 2019). The symptoms of RLS generally occur or worsen at rest or inactivity in the evening, which can be at least partially relieved by movements (Trenkwalder et al., 2018). Previous studies have emphasized the major role of iron in the disease (Connor et al., 2017). In addition, one of the primary medications for the disease is $D_{2} / D_{3}$ dopamine (DA) agonists (Garcia-Borreguero and Cano-Pumarega, 2017), whereas refractory RLS can be treated with opioids (Silber et al., 2018).

To date, no neurodegeneration has been found in RLS patients. However, emerging studies suggest that changes in the striatum may underlie the pathogenesis of RLS (Earley et al., 2017; Lanza et al., 2017; Rizzo et al., 2017). The striatum, which is comprised of the caudate and putamen, serves as the first recipient for most of the excitatory input from the cortex and thalamus to the basal ganglia (Haber, 2016). Approximately $95 \%$ of striatal neurons are GABAergic medium spiny neurons (MSNs), which are traditionally subdivided into two subtypes by DA receptor expression (Purves et al., 2001b). Generally, $D_{1}$ DA receptor $\left(D_{1} R\right)$-expressing MSNs function in the direct pathway and are thought to facilitate wanted movements and pronociceptive effects (Soares-Cunha et al., 2016). In contrast, MSNs in the indirect pathway mainly express $D_{2}$ DA receptors $\left(D_{2} R s\right)$. These MSNs are likely to be involved in the suppression of unwanted movement and the generation of antinociceptive effects (SoaresCunha et al., 2016). Additionally, 1-2\% of striatal neurons are cholinergic interneurons (Chls; Zucca et al., 2018). MSNs regulate the activity of Chls through GABA and endogenous opioids (Lim et al., 2014), while Chls influence the activity of MSNs through M1, M4, and possibly nicotinic acetylcholine (ACh) receptors on MSNs (Bordia et al., 2016). Previous clinical studies have shown decreased $D_{2} R$ expression but increased phosphorylated $\mathrm{TH}$ in the putamen (Connor et al., 2009). Brain imaging studies show decreased striatal DA transporter (DAT; Earley et al., 2011) and $D_{2} R$ binding potential (Michaud et al.,

\footnotetext{
Y. Li contributed unpublished reagents/analytic tools.

This work was supported by National Institute of Health Grants R01NS082244 and R21NS065273; Restless Legs Syndrome Foundation; and the National High Magnetic Field Laboratory's Advanced Magnetic Resonance Imaging and Spectroscopy (AMRIS) Facility (National Science Foundation Cooperative Agreement DMR-1157490 and the State of Florida).

${ }^{\wedge}$ S.L. and H.X. contributed equally to this work.

Acknowledgements: We thank Dr. David Lovinger and his lab for helping with striatal brain slice recording.

Correspondence should be addressed to Yuqing $\mathrm{Li}$ at yuqing.li@ neurology.ufl.edu.

https://doi.org/10.1523/ENEURO.0277-19.2019

Copyright (C) 2019 Lyu et al.

This is an open-access article distributed under the terms of the Creative Commons Attribution 4.0 International license, which permits unrestricted use, distribution and reproduction in any medium provided that the original work is properly attributed.
}

2002; Earley et al., 2013). Despite these observed alterations of the striatal dopaminergic system associated with RLS, the exact functions of the striatum, especially MSNs, in the disease development are largely unknown.

Genome-wide association studies (GWAS) have implicated up to 19 risk loci, including BTBD9, as genetic risk factors of RLS (Schormair et al., 2017; Jiménez-Jiménez et al., 2018). BTBD9 codes for a protein belonging to the BTB (POZ) protein family, which modulates transcription, cytoskeletal arrangement, ion conductance and protein ubiquitination (Stogios and Privé, 2004; Stogios et al., 2005). An alteration in hippocampal synaptic plasticity and neurotransmission has been found in Btbd9 knockout (KO) mice (DeAndrade et al., 2012b). Loss of the BTBD9 homolog in Drosophila melanogaster results in increased motor activity, decreased DA levels, and disrupted sleep patterns (Freeman et al., 2012). Similarly, the systematic Btbd9 KO mice showed motor restlessness, thermal hypersensitivity, and a disruption in sleep structure (DeAndrade et al., 2012a). Therefore, the systematic Btbd9 $\mathrm{KO}$ can be considered as a valuable disease mouse model to study the pathophysiology of RLS (DeAndrade et al., 2012a; Allen et al., 2017).

To elucidate the impact of striatal neurons on the generation of RLS-like phenotypes, we performed in vivo manganese-enhanced MRI (MEMRI) with the systematic Btbd9 KO mice and mapped the functional neural activity in the basal ganglia circuits. We next conducted electrophysiological recordings to observe both intrinsic and spontaneous firing activity of MSNs and Chls in the striatum. Moreover, we selectively deleted Btbd9 in either striatal MSNs or Chls and conducted behavioral studies.

\section{Materials and Methods}

\section{Mice}

The generation of the systematic Btbd9 KO mice

The homozygous Btbd9 $\mathrm{KO}$ male mice used in MRI imaging were generated as described previously (DeAndrade et al., 2012a). The systematic Btbd9 KO mice used in the electrophysiological recording were generated from a line of Btbd9 loxP mice imported from the European Mouse Mutant Archive (EMMA; ID: 05554). In this line, the fourth exon of the Btbd9 gene was flanked by loxP sites (floxed). We first removed neomycin selection cassette by crossing with FLP mice (The Jackson Laboratory stock 126 no. 003946) to obtain Btbd9 loxP mice, which was then crossed with a general cre deletor to obtain Btbd9 $\mathrm{KO}$ allele. Heterozygous Btbd9 $\mathrm{KO}$ mice were interbred to produce experimental homozygous Btbd9 $\mathrm{KO}$ mice and the wild-type (WT) littermate controls.

\section{The generation of specific Btbd9 $\mathrm{KO}$ mice}

The MSNs-specific Btbd9 KO mice (Btbd9 sKO) were generated by breeding Btbd9 loxP mice with Rgs9-cre mice, in which the cre gene was inserted at the $3^{\text {' end of }}$ the Rgs9 gene (Dang et al., 2006). Double heterozygous mice (Rgs9-cre $\pm B t b d 9$ loxP \pm ) were used for breeding with heterozygous (Btbd9 loxP \pm ) or homozygous Btbd9 loxP mice (Btbd9 loxP-/-) to generate the conditional KO animals (Rgs9-cre $\pm B t b d 9$ loxP-/-) and control groups, including WT littermates, animals only expressing Rgs9- 
cre (Rgs9-cre \pm ) and animals only having loxP sites in one (Btbd9 loxP \pm ) or both of the DNA strands (Btbd9 loxP-/-). PCR was used for genotyping the Rgs9-cre (forward: TGC TCA AAA ATT GTG TAC CTT TAG C; reverse: CAA CAC CCC ATT CGC TTT TTC CA) and the loxP sites (forward: ACA TCA CCC ATT ACT TAG AAC CTC; reverse: CAC AGC TAT TTC CTG TCA TTC TGG ACA).

The Chl-specific Btbd9 KO mice (Btbd9 ChKO) were generated by breeding Btbd9 loxP mice with Chat-cre mice (The Jackson Laboratory; stock 006410), in which the neo cassette had been removed by crossing with FLP mice. Breeding was conducted as outlined for Btbd9 sKO above. PCR was used for genotyping the Chat-cre (forward: ATC TCC GGT ATT GAA ACT CCA GCG C; reverse: CAC TCA TGG AAA ATA GCG ATC). To confirm the specific deletion of Btbd9 in the striatum, we dissected out brain regions following the protocol (Spijker, 2011) and PCR was conducted with primers specific for recombined locus (forward: AAG GCG CAT AAC GAT ACC ACG AT; reverse: TGG TGA TTC AAA TCT CCT TCC AAC ACA; Fig. 4C).[AQ3] Experimental mice were housed in standard mouse cages at $21^{\circ} \mathrm{C}$ under normal $12 / 12 \mathrm{~h}$ light/ dark cycle (12 LD) condition. The protocol for the study received prior approval by the Institutional Animal Care and Use Committee, and all studies were conducted in accordance with the United States Public Health Service's Policy on Humane Care and Use of Laboratory Animals.

\section{Quantitative RT-PCR (qRT-PCR)}

qRT-PCR was performed as described before (Yokoi et al., 2011) to determine whether exon 4 was deleted in mice after cre-mediated recombination. In brief, three Btbd9 sKO and three control adult male mice were sacrificed, and several brain regions (striatum, cerebral cortex and cerebellum) were harvested and flash frozen in liquid nitrogen. RNA was extracted using an RNAeasy Mini kit (QIAGEN) according to the manufacturer's instructions. Next, cDNA was made using SuperScript III reverse transcriptase (Invitrogen). PCR primers specific to Btbd9 exons 4 and 5 (forward: GAC TCT TGT CTC CGG ATG CT; reverse: TCA CAA CCT GAG CCC CAT AC); $\beta$-actin (forward: CAC CCG CGA GCA CAG CTT CTT TG; reverse: AAT ACA GCC CGG GGA GCA TCG TC). The expression of Btbd9 mRNA was measured and normalized by BioRad CFX manager 3.1.

\section{MEMRI}

$\mathrm{MnCl}_{2}$ (manganese chloride) pretreatment

MEMRI was performed as described previously (Perez et al., 2018; Zubcevic et al., 2018). Before the treatment, the animals used in the experiment were handled every two weeks and acclimatized to the investigator. Manganese (II) chloride tetrahydrate (Sigma-Aldrich Chemical Co.) was dissolved in distilled deionized water and sterilely filtered before administered intraperitoneally at a dose of $70 \mathrm{mg} / \mathrm{kg} / \mathrm{ml}$. After injections, mice were returned to their home cage and imaged after $20-24 \mathrm{~h}$ as previously reported (Perez et al., 2013).
MRI

Images were collected by a 4.7 Tesla Magnex Scientific scanner under the control of Agilent Technologies VnmrJ 3.1 console software. A 38-mm quadrature transmit/receive radio frequency coil tuned to $200 \mathrm{MHz}$ was used (Insight Neurolmaging Systems, LLC). Mice were anesthetized with $2.0 \%(0.1 \mathrm{l} / \mathrm{min})$ delivered in $100 \%$ oxygen for 30-60 s. Then the level of isoflurane was maintained between $1.0 \%$ and $1.25 \%$ throughout the entire setup and imaging session, during which the respiratory rates were monitored continuously and sustained between 20 and 30 beats per minute by adjusting isoflurane levels between the range. Placed prone on custom-size plastic bed with a respiratory pad placed underneath the abdomen, body temperatures of the mice were maintained using a warm air recirculation system (SA Instruments, Inc.). The head and incisors of mice were secured on the front end of the plastic bed to minimize motion. The front half of the bed was aligned and clamped inside the quad RF coil and placed inside the isocenter of the scanner. Images were acquired at 4.7 Tesla using a T1-weighted spin echo pulse sequence with the following parameters: repetition time $=300 \mathrm{~ms}$, echo time $=12 \mathrm{~ms}$, the field of view $=19.2 \times 19.2$, slice thickness $=0.8 \mathrm{~mm}, 12$ slices. Total scan time per mouse was $30 \mathrm{~min}$.

\section{Electrophysiological recording}

Slice preparation

Experiments were conducted as described previously (Pappas et al., 2015; Augustin et al., 2018). Recordings of MSNs were conducted with three Btbd9 KO and five WT male littermates at an average age of four months. Recordings of Chls were performed with four Btbd9 $\mathrm{KO}$ and five WT male littermates with an average age of four months, or with three Btbd9 ChKO and three control males with an average age of five months. Investigators who conducted the experiments were blind to the genotypes. Animals were sacrificed, and the brains were rapidly removed; $300 \mu \mathrm{m}$-thick coronal brain slices containing the dorsal striatum were cut in ice-cold, oxygenated cutting saline: $180 \mathrm{mM}$ sucrose, $2.5 \mathrm{mM} \mathrm{KCl}$, $1.25 \mathrm{mM} \mathrm{NaH}_{2} \mathrm{PO}_{4}, 25 \mathrm{mM} \mathrm{NaHCO}_{3}, 10 \mathrm{mM}$ D-glucose, 1 $\mathrm{mM} \mathrm{CaCl}, 10 \mathrm{mM} \mathrm{MgCl}$, and $10 \mathrm{mM}$ glucose with a Vibratome (Leica VT 1000s). Slices were recovered in a holding chamber for $30 \mathrm{~min}$ at $35^{\circ} \mathrm{C}$ with artificial CSF (ACSF). Final concentrations of ACSF: $126 \mathrm{mM} \mathrm{NaCl}, 2.5$ $\mathrm{mM} \mathrm{KCl}, 1.25 \mathrm{mM} \mathrm{NaH} \mathrm{PO}_{4}, 25 \mathrm{mM} \mathrm{NaHCO}, 2 \mathrm{mM}$ $\mathrm{MgCl}_{2}, 2 \mathrm{mM} \mathrm{CaCl}$, and $10 \mathrm{mM}$ glucose, $\mathrm{pH} 7.3$ with $\mathrm{KOH}$, osmolality $290-300$ mOsm. The slices were then incubated at room temperature.

\section{Cell identification}

The slices were placed in a recording chamber and continuously perfused with ACSF that was bubbled via $5 \% \mathrm{CO}_{2}$ and $95 \% \mathrm{O}_{2}$ at a rate of $1.5 \mathrm{ml} / \mathrm{min}$ while being visualized with an upright microscope (Zeiss) using a $40 \times$ water-immersion objective with infrared optics. MSNs were identified by the somatic size and basic membrane properties including input resistance, membrane capacitance, and time constant. Chls were recognized based on 
morphology and size, as they are irregularly polygonal with large cell soma (>20 $\mu \mathrm{m})$.

\section{Cell-attached and whole-cell recordings}

For MSNs, all experiments were recorded at $32^{\circ} \mathrm{C}$ by a dual automatic temperature controller (TC-344B). Cellattached recording patch pipette (6-10 $\mathrm{M} \Omega$ ) contained following solutions: $125 \mathrm{mM} \mathrm{K-gluconate,} 8 \mathrm{mM} \mathrm{NaCl}, 10$ mM HEPES, 2 mM MgATP, 0.3 mM NaGTP, and $0.2 \mathrm{mM}$ EGTA (pH 7.25-7.3, osmolality 290-300 mOsm) and was used for voltage and current clamp recordings. Access resistances were $<30 \mathrm{M} \Omega$. Spontaneous postsynaptic currents were recorded in ACSF. To minimize the contribution of $\mathrm{GABA}_{\mathrm{A}}$ receptors, we held cells at $-70 \mathrm{mV}$ with an application of $50 \mu \mathrm{M}$ picrotoxin solution, which can abolish the activation of $\mathrm{GABA}_{\mathrm{A}}$ receptors. Next, at holding potential $-65 \mathrm{mV}$, injection of depolarizing 50-pA current pulse of 300-ms duration evoked spike firing when the membrane potential reaches the firing threshold under current clamp configuration in a brain slice. This process was repeated at 10 increasingly depolarized potentials with incremental current steps (50 pA).

For Chls, electrodes for cell-attached recordings were filled with a K-gluconate-based solution containing the following concentrations: $112.5 \mathrm{mM} \mathrm{K}$-gluconate, $4 \mathrm{mM}$ $\mathrm{NaCl}, 17.5 \mathrm{mM} \mathrm{KCl}, 0.5 \mathrm{CaCl}_{2}, 5 \mathrm{mM} \mathrm{MgATP}, 1 \mathrm{mM}$ NaGTP, $5 \mathrm{mM}$ EGTA, and $10 \mathrm{mM}$ HEPES; with pH 7.2 (270-280 mOsm) and resistance of 5-10 M . Positive pressure was applied to the patch electrode as it approached the Chls. Suction was applied to the electrode to create a seal (>5 G $\Omega$ ) between the recording pipette and cell membrane. Action potential current was recorded in a voltage-clamp mode that maintained an average of $0-p A$ holding current. After breaking through the cell membrane, cellular properties (capacitance, input resistance, and time constant) were recorded at a membrane potential of $-70 \mathrm{mV}$. Electrode access resistance was maintained throughout at $<30 \mathrm{M} \Omega$. Resting membrane potential was recorded in current clamp mode. Action potential for current step recording was triggered using depolarizing currents steps of $300 \mathrm{~ms}$.

Data acquirement and detection were the same as previously described (DeAndrade et al., 2012b). Recordings were made from targeted cells in the striatum using infrared differential interference contrast microscopy and an Axopatch 1D amplifier (Molecular Devices). Data were acquired using pClamp 10 software. Signals were filtered at $5 \mathrm{kHz}$, digitized at $10 \mathrm{kHz}$ with a DigiData 1440 (Molecular Devices). Events were detected using the Mini Analysis Program (Synaptosoft) with parameters optimized for each cell and then visually confirmed before analysis. The peak amplitude, $10-90 \%$ rise time and the decay time constant were measured based on the average of all events aligned by the rising phase.

\section{Immunofluorescence staining}

Rgs9-cre mice were bred with GFP mice imported from The Jackson Laboratory (stock 007906) to obtain Rgs9cre and GFP double heterozygous mice to map Rgs9-crepositive neurons. As described previously (Dang et al., 2006), the mice were anesthetized and perfused with ice-cold 0.1 M PBS (pH 7.4) followed by 4\% paraformaldehyde in 0.1 M PB (pH 7.4). The brains were soaked in $4 \%$ paraformaldehyde-PB at $4^{\circ} \mathrm{C}$ overnight and then incubated in $30 \%$ sucrose in $0.1 \mathrm{M}$ PBS at $4^{\circ} \mathrm{C}$ until the brains sank to the bottom. The brains were frozen with dry-ice powder and cut coronally into $40-\mu \mathrm{m}$ sections with a Histoslide 2000 sliding microtome (Reichert-Jung). Sections were sequentially rinsed $5 \mathrm{~min}$ each in $0.5 \%$ Triton X-100, 0.02 M PBS; 0.1\% Triton X-100, 0.02 M PBS; $10 \mathrm{mM}$ glycine in $0.1 \mathrm{M}$ PBS for three times; $0.5-\mathrm{ml}$ $2 \%$ gelatin in $0.1 \mathrm{M} \mathrm{PBS} ; 10 \mathrm{mM}$ glycine in $0.1 \mathrm{M} P B S$; and $0.1 \%$ BSA in $0.1 \mathrm{M}$ PBS. Then tissues were incubated with the primary antibody, 1:50 goat anti-choline acetyltransferase (AB144P; Millipore), dissolved in $100 \mu \mathrm{l} 1 \%$ BSA, $0.1 \mathrm{M}$ PBS at $4^{\circ} \mathrm{C}$ overnight. The next day, tissues were washed for six times with $0.1 \%$ BSA, $0.1 \mathrm{M} \mathrm{PBS}$, followed by incubation with secondary antibody, 1:200 Cy3conjugated AffiniPure donkey anti-goat IgG (705-265-003; Jackson ImmunoResearch). After washing, the sections were mounted on glass slides with VECTASHIELD Antifade Mounting Medium (H-1400) and cover-slipped.

\section{Behavioral studies}

Thirty-minute open field

Eight Btbd9 sKO male mice and seven male littermates with an average age of 15 months, or seven Btbd9 ChKO (three males, four female) and nine controls (five males, four female) with an average age of seven months, were used in the 30-min open field analysis as previously described (DeAndrade et al., 2012a). Briefly, each mouse was placed in the center of a VersaMax Legacy open field apparatus connected to a computerized Digiscan System (Accuscan Instruments, Inc.) and continuously monitored for $30 \mathrm{~min}$. The apparatus contains infrared sensors along the walls that detect any breaks in the beams. Bright illumination ( $\sim 1 \mathrm{k}$ lux at the center by a $60-\mathrm{W}$ white bulb) was focused on the center of each field.

\section{Wheel running}

Eight Btbd9 sKO mice (seven males, one female) and 13 control mice (eleven males, two females) with an average age of four months, or six Btbd9 ChKO male mice and seven male littermates with an average age of two months, were maintained on a 12 LD cycle for $7 \mathrm{~d}$. Wheelrunning activity (DeAndrade et al., 2012a) was recorded as the number of wheel revolutions occurring during 5 min bins and analyzed using Lafayette Instrument Activity Wheel Monitor software. The activity from the last $4 \mathrm{~d}$ was included in the data analysis, grouped by light phase and dark phase.

\section{Continuous open field}

Seven male Btbd9 sKO mice and five male littermates with an average age of five months or three Btbd9 ChKO male mice and four male littermates with an average age of two months were used in the long-term open field analysis modified from 30-min open field test (Meneely et al., 2018). Each mouse was placed in the center of a VersaMax Legacy open field apparatus with enough corncob bedding, food, and water. Breaks in the beams were decoded by VERSDATA version 2.70-127E (AccuScan Instruments Inc.) into behavioral patterns. Batch 1 data for 
Btbd9 ChKO mice were collected every $1 \mathrm{~h}$. Other data were recorded every 15 min throughout the experiment. Data from the last $4 \mathrm{~d}$ were separated into light and dark phases, and the total distances during each phase were combined and coded as day 4-7, and night $4-7$, respectively. The analysis was conducted based on all four periods in each phase. Separately, the total distances for each $15 \mathrm{~min}$ of the last $4 \mathrm{~d}$ were recoded for sleep analysis. If the total distance traveled in 15 min was 0 , the mouse was considered as sleeping, and the data were coded as 0; otherwise, the mouse was considered as awake, and the data were coded as 1 .

\section{Tail flick test}

Nine male Btbd9 sKO mice and nine male littermates with an average age of eight months were tested for the perception of warm stimuli. Each mouse was placed in an acrylic restrainer with the distal end of its tail protruding on a metal surface maintained at $55^{\circ} \mathrm{C}$. The timer was turned on once the tail touched the surface and immediately stopped when the mouse flicked its tail away from the heat. The latency to respond was limited to $90 \mathrm{~s}$ to prevent injury to the mouse.

\section{Experimental design and statistical analysis}

Images were processed and analyzed as previously reported (Perez et al., 2013). $\mathrm{Mn}^{2+}$ accumulation in active neurons produces signal intensity increases in T1 images. However, as this is a non-quantitative approach to measure activity and because there is scan-to-scan intensity variation independent of $\mathrm{Mn}^{2+}$, we normalized images based on their individual variance. Using this normalization approach, where surpassing a normalized threshold value of 1 indicates increased activity associated with $\mathrm{Mn}^{2+}$ administration, we have observed significant differences between $\mathrm{Mn}^{2+}$ administered and non-treated rodents. Image processing was conducted using ITK-SNAP (http://www.itksnap.org), and image math scripts were available on FSL (fslmaths; http://www.fmrib.ox.ac.uk/ fsl/). Scans were aligned with a segmented atlas of the adult mouse brain using an automated affine linear registration tool from FSL (Jenkinson et al., 2012). Each scan was converted to a $z$ value map through a voxel-wise normalization procedure. The mean signal intensity across the entire extracted brain volume $\left(x^{-}\right)$was subtracted from each voxel (xi) and then divided by the variance $(\sigma)$. A pre-set threshold of $z \geq 1$ was selected based on prior observation of individual datasets and a close inspection of their intensity distribution histograms. All voxels with $z$ score values below this threshold were set to zero. Thus, the voxels exceeding the threshold value of $z \geq 1$ were considered in our statistical analysis as having higher signal intensities (quantified as the number of voxels above a $z$ value of 1 ). Mean number of voxels for each region of interest (ROI) was compared using an unpaired two-tailed $t$ test (homoscedastic variances, $\alpha \leq$ 0.05).

Electrophysiological data were analyzed by logistic regression (not normally distributed) or mixed model ANOVA (SAS statistic package, normally distributed) with cell identification number nested within animal identifica- tion number. Open field data were analyzed by mixed model ANOVA and adjusted for multiple comparisons using the Benjamini-Hochberg-Yekutieli false discovery rate (FDR; $p<0.05$ ). Data obtained from wheel running study was analyzed by logistic regression with a negative binomial distribution. Total distances of continuous open field were analyzed by logistic regression with a gamma distribution while sleep analysis was conducted with binomial logistic regression modeling the probability of waking. Tail flick data were processed by logistic regression with a gamma distribution. GEE model in the logistic regression normalized WT or control groups in terms of current steps, wheel running, continuous open field, and tail flick to 0 without the error bar. Age and gender were used as covariates in all analysis.

To generate the hourly wheel-running activity presented in Figure $5 B$, we summed the interval counts during each hour for each animal. Wheel-running activity during the last $96 \mathrm{~h}$ was analyzed. Hence each animal had 4 data points for each hour. The average interval counts within each hour were calculated for each genotype. The $p$ values, calculated by the unpaired Student's test, were marked above hours in the figure. To generate the hourly probability of waking in Figure 5/, we determined the sleep status by the total distance traveled during $15 \mathrm{~min}$ in the long-term open field test as mentioned above. Therefore, there were 4 data points for each animal during each hour, which were coded from 1 and 4 as "sample." Last 4 d' open field activity was analyzed. Hence each animal had $4 \mathrm{~d}$ of data, which were coded from 1 to 4 as "period." The probability of waking was calculated from a genotype and hour two-way interaction with repeated measurement of the period, hour, and sample using SAS logistic regression with a binomial distribution. For each genotype, SAS normalized probability of waking during each hour to the probability of the last hour either during the day or night period. The probability of waking at 6 P.M. of the control mice was set as 1 , and the probabilities of the waking of other hours of the control mice were calculated relative to that of 6 P.M. To calculate the relative difference between ChKO mice and controls during each hour, we sorted the data by the hour and analyzed the probability of waking for each genotype with repeated measurement of period and sample using SAS logistic regression with a binomial distribution. The $p$ values were marked above hours in the figure. The probability of waking of the ChKO mice was derived from the relative difference between the ChKO mice and the control mice.

\section{Results}

\section{Increased striatal neural activity in fMRI study with the systematic Btbd9 KO mice}

To study the role of the striatum in RLS pathogenesis, we first used MEMRI imaging to determine the striatal neural activity in the systematic Btbd9 KO mice. MEMRI has been extensively used to track $\mathrm{Ca}^{2+}$-dependent synaptic activity (Lu et al., 2007; Hsu et al., 2008; Chiu et al., 2015; Dudek et al., 2015; Perrine et al., 2015). As a calcium analog, $\mathrm{Mn}^{2+}$ enters active synapses through voltage-gated calcium channels (Fukuda and Kawa, 1977; 

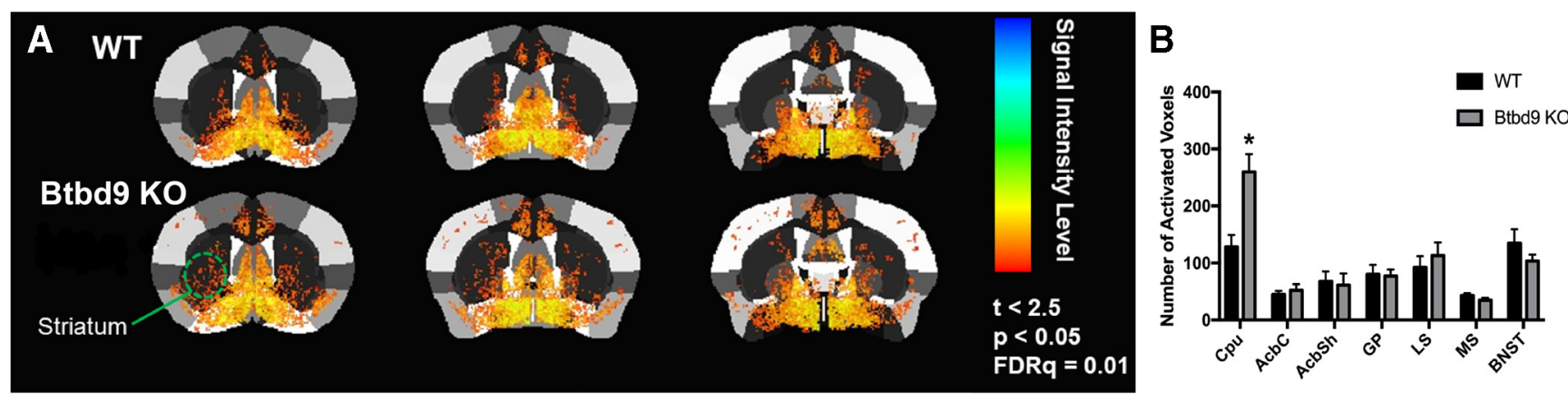

Figure 1. A, Coronal views of the averaged signal intensity from Btbd9 $\mathrm{KO}$ and WT controls. $\boldsymbol{B}$, Btbd9 $\mathrm{KO}$ had significant increased neural activity in caudate and putamen and in the cerebral cortex. No difference was observed in other brain regions under investigation. Bars represent means plus SEs. Cpu: caudate/putamen; AcbC: nucleus accumbens core; AcbSh: nucleus accumbens shell; GP: globus pallidus; LS: lateral septal nucleus; MS: medial septal nucleus; BNST: bed nucleus of the stria terminalis; $* p<0.05$.

Narita et al., 1990) and is sequestered and transynaptically transported antero- and retrogradely across active neural circuits (Sloot and Gramsbergen, 1994; Pautler et al., 1998; Takeda et al., 1998a, b; Saleem et al., 2002; Murayama et al., 2006). The presence of the paramagnetic $\mathrm{Mn}^{2+}$ ion in the brain increases longitudinal relaxation rates and enhances signal intensity in $\mathrm{T} 1$ weighted scans, and is used for functional mapping of synaptic activity (Duong et al., 2000). Here, after $\mathrm{Mn}^{2+}$ was injected into the mice, the images of ROI were acquired (Fig. 1A). The result showed increased neuronal activity in the cerebral cortex of the systematic Btbd9 KO mice, indicating an increased cortical input to the striatum. This will be addressed in detail in a separate manuscript. In the striatum, which is the focus of the current study, there was a significant increase in the caudate/putamen (Fig. 1B, $p=$ 0.006 , unpaired two-tailed $t$ test), indicating increased neural activity specifically in the striatum. Increased entry of $\mathrm{Mn}^{2+}$ likely through voltage-gated $\mathrm{Ca}^{2+}$ channels also suggest an increase in $\mathrm{Ca}^{2+}$-dependent neural activity.

\section{More excitable MSNs but decreased Chl activity in the systematic Btbd9 KO mice}

As the first recipient for the excitatory input from almost all of the cortex, the striatum is mostly composed of MSNs (>95\%; Cox and Witten, 2019). To determine the source of increased neural activity in striatum revealed by fMRI study, we did whole cell patch-clamp recording in brain slices. The result indicated that the resting membrane potential of the systematic Btbd9 $\mathrm{KO}$ cells was higher than the WTs (Fig. 2D, $p=0.03$, logistic regression with a gamma distribution). No change was found in membrane capacitance (Fig. $2 A, p=0.93$, logistic regression with a gamma distribution), input resistance (Fig. 2B, $p=0.58$, logistic regression with a gamma distribution) and decay time constant (Fig. $2 C, p=0.58$, logistic regression with a gamma distribution). We then tested whether the intrinsic excitability of striatal MSNs was affected by the loss of Btbd9. Depolarizing current steps were injected to the MSNs of both Btbd9 KOs and WTs (Fig. 2E). There was no significant difference in the frequency-current relationship (Fig. $2 F, G, p=0.51$, logistic regression with a negative binomial distribution), am- plitude, rise, and decay time (data not shown). Our results indicated that there was no change in the intrinsic excitability of the KO MSNs.

MSNs are strongly driven by glutamatergic inputs (Purves et al., 2001a). To test whether loss of BTBD9 affects excitatory synaptic transmission in MSNs, we recorded sEPSCs (Fig. 2H). There were no alterations in the rise time (Fig. $2 K, p=0.60$, logistic regression with a gamma distribution), the decay time (Fig. $2 L, p=0.33$, logistic regression with a gamma distribution), and the frequency (Fig. $2 I, p=0.11$, logistic regression with a gamma distribution) of spontaneous postsynaptic currents. However, the systematic Btbd9 KO mice showed a significantly larger amplitude of SEPSC (Fig. $2 \mathrm{~J}, p=$ 0.004 , logistic regression with a gamma distribution). The increased amplitude may be due to the increased presynaptic quantal size, increased postsynaptic functional AMPA receptor, or both. The result suggests that there are significantly enhanced excitatory inputs to the KO MSNs. In combination with the increased resting membrane potential found in the KO MSNs, the result indicates that BTBD9 deficiency may cause striatal MSNs to be more excitable.

Abnormality in ACh neurotransmission plays an important role in movement disorders like Parkinson's disease and dystonia (Bohnen and Albin, 2011; Dang et al., 2012; Lim et al., 2014; Eskow Jaunarajs et al., 2015). Furthermore, another RLS susceptibility gene, MEIS1, has been linked to the development of striatal Chls (Spieler et al., 2014). Here, to better understand the striatal physiology in Btdb9 KO mice and RLS, we recorded both spontaneous activity (Fig. $3 C$ ) and intrinsic excitability of Chls (Fig. $3 A$ ). We found that Chls of the systematic Btbd9 KO mice had decreased intrinsic excitability (Fig. $3 B, p=0.049$, logistic regression with a negative binomial distribution) and spontaneous firing activity (Fig. $3 D, p=0.04$, ANOVA). It is known that MSNs inhibit the activity of Chls through GABA and opioid receptors (Lim et al., 2014). Therefore, the alterations found in Chls can either be a cellautonomous effect of BTBD9 deficiency or the response to increased activity of MSNs. This was further explored in Btbd9 ChKO mice. 
A

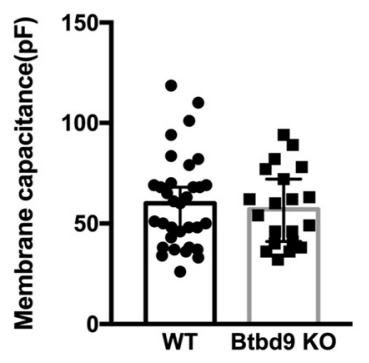

E

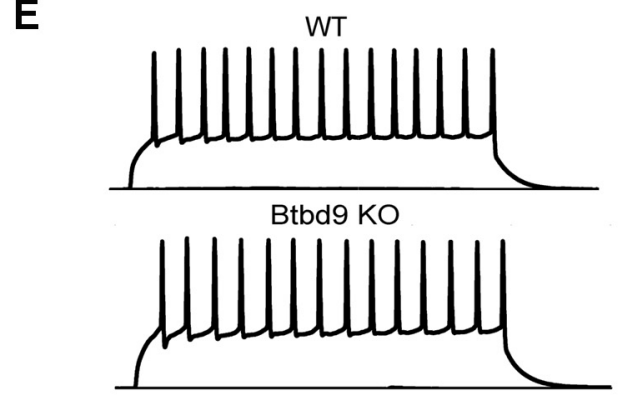

$250 \mathrm{pA}$

OpA

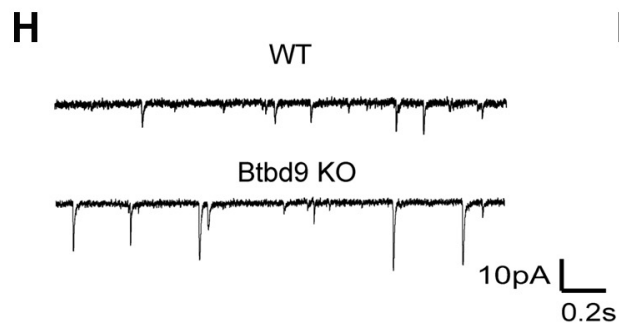

B

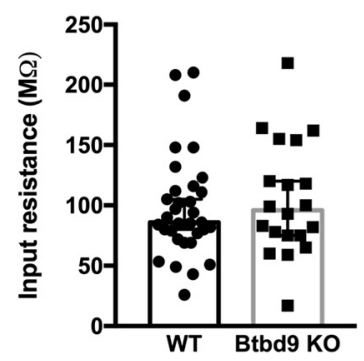

C

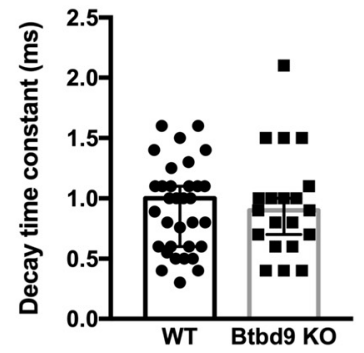

D

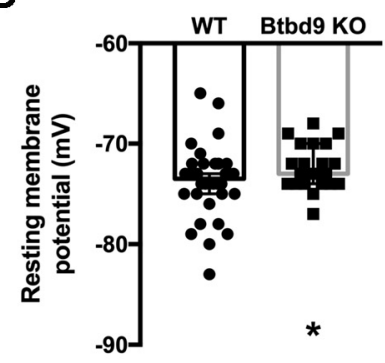

F
G

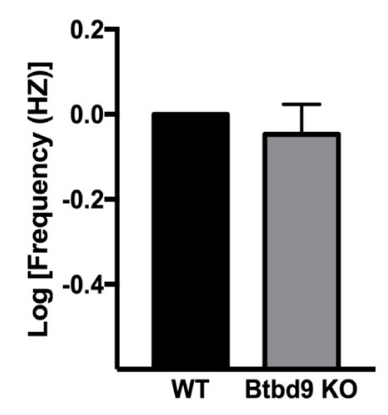

Figure 2. Whole-cell patch-clamp recording of MSNs from the systematic Btbd9 KO mice and their WT littermates. A-C, Btbd9 KO MSNs $(n=20)$ did not have changes in membrane capacitance, input resistance and decay time constant compared with the WT MSNs $(n=33)$. $\boldsymbol{D}$, Btbd9 KO MSNs $(n=22)$ had increased resting membrane potential compared with the WTs $(n=$ 34). $\boldsymbol{E}$, Representative responses to the injected currents at $250 \mathrm{pA}$ of KO $(n=21)$ and WT $(n=34) \mathrm{MSNs}$. $\boldsymbol{F}$, The frequency-current relationship for WT and Btbd9 KO MSNs. G, The response of KO MSNs to the injected currents was not significantly different from the WT MSNs. $\boldsymbol{H}$, Representative sEPSC traces of KO $(n=20)$ and WT $(n=30)$ MSNs. I, The frequency of spontaneous firing was similar between the two groups. J, Btbd9 KO MSNs had a higher amplitude of sEPSC than the WT. $\boldsymbol{K}, \boldsymbol{L}$, Both the rise and decay time were not different between Btbd9 homozygous KO and WT MSNs. GEE model normalized the WT group in the bar graph of $\boldsymbol{B}$ to 0 without the error bars. Data in $\boldsymbol{A}-\boldsymbol{D}, \boldsymbol{I}-\boldsymbol{L}$ were presented as median with $95 \%$ confidence intervals $(\mathrm{Cls}) ; * * * p<0.005, * p<0.05$.

\section{Generation and molecular characterization of Btbd9 sKO mice}

To further study the critical role of the striatum in RLS, we generated two conditional KO mouse models in which the Btbd9 gene was selectively knocked out either in the MSNs or Chls (Fig. 4A). Specifically, we interbred Rgs9cre mice with Btbd9 loxP mice to obtain Btbd9 sKO mice. The transcription of $B t b d 9$ gene was quantified by qRTPCR. As expected, there was a significant reduction of Btbd9 mRNA in the striatum compared to control littermates (Fig. $4 B, p=0.047$, paired two-tailed $t$ test), but not in the cerebral cortex or cerebellum (Fig. $4 B$, cerebral cortex, $p=0.51$; cerebellum, $p=0.28$; both paired two-tailed $t$ test). To future confirm tissue specificity of the $\mathrm{KO}$, we dissected out different brain regions from the Btbd9 sKO mice and their controls. DNAs were extracted from these different brain regions, and PCR reactions were conducted. Only the DNA extracted from the striatum of Btbd9 sKO mice showed the recombined band (Fig. $4 C$ ), indicating that the $\mathrm{KO}$ was restricted to the striatum. It is worth noting that the remaining Btbd9 expression in the striatum can be accounted for by the small subset of interneurons $(<4 \%)$ that do not express cre, and non-neuronal cells such as glial cells. To determine whether Chls express Rgs9-cre, we crossed Rgs9-cre mice with GFP indicator mice and generated Rgs9-creGFP mice. There were no overlaps between 100 randomly selected, ChAT-positive neurons with any of the GFPpositive neurons (Fig. 4D). The results suggest that Rgs9cre does not induce gene recombination in Chls and Btbd9 gene is mostly knocked out in the MSNs of Btbd9 sKO mice. 
A

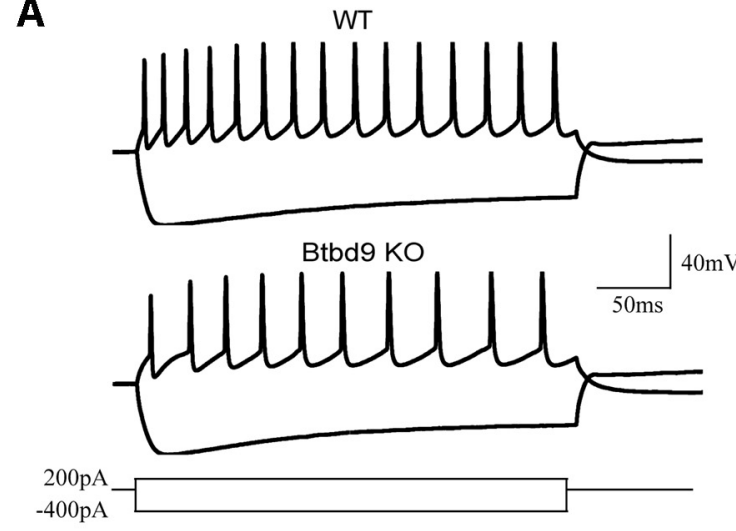

C

WT
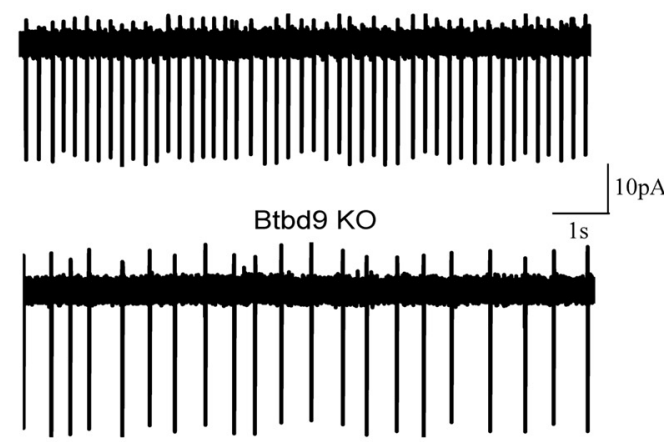

B
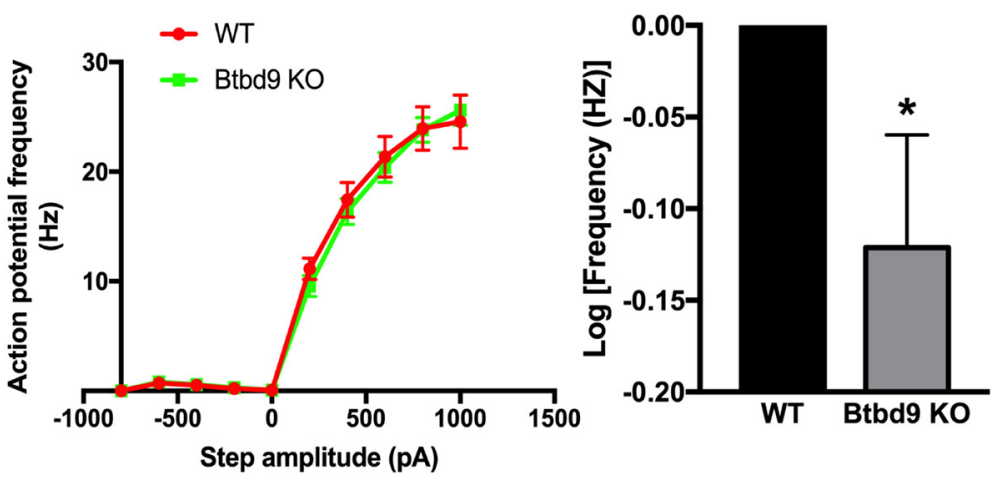

D

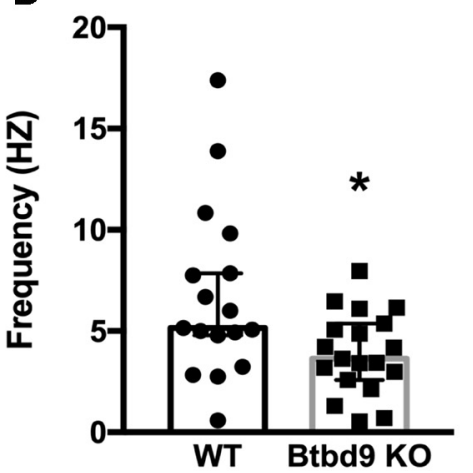

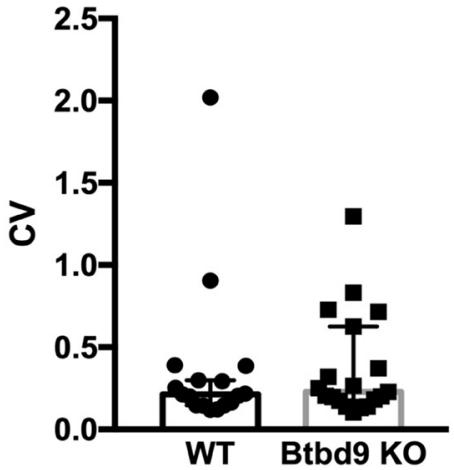

Figure 3. Electrophysiological recording of Chls from the systematic Btbd9 KO mice and their WT littermates. A, Representative responses to the injected currents at $200 \mathrm{pA}$ of KO $(n=20)$ and WT $(n=14)$ Chls. $\boldsymbol{B}$, The frequency-current relationship for KO and WT Chls. KO showed decreased firing frequency compared with the WT. WT was normalized to 0 in log transformation. $\boldsymbol{C}$, Representative traces of spontaneous firings of KO $(n=19)$ and WT $(n=17)$ Chls. $\boldsymbol{D}$, Btbd9 KO mice had decreased firing frequency, but no change in firing regularity in Chls. GEE model normalized the WT group in the bar graph of $\boldsymbol{B}$ to 0 without the error bars. Data in $\boldsymbol{D}$ were presented as median with $95 \% \mathrm{Cl}$. CV: coefficient of variance; $* p<0.05$.

\section{RLS-like phenotypes in Btbd9 sKO but not in Btbd9 ChKO mice}

A principal feature of RLS is a desire to move (Ferré et al., 2019). Previous mouse or fruit fly models of RLS have shown increased activity levels (DeAndrade et al., 2012a; Freeman et al., 2012). Therefore, we used an open field activity chamber to assess the total activity levels of the Btbd9 sKO and Btbd9 ChKO mice. In the short-term 30-min open field test, we observed that although there was no alteration found with Btbd9 ChKO mice [Fig. $5 F$, total distance, $p=0.69$; clockwise (CW), $p=0.29$; counter-CW (CCW), $p=0.70$; all ANOVA], Btbd9 sKO mice exhibited significantly increased total distance traveled (Fig. 5A, total distance, adjusted $p=0.01$, ANOVA) and vertical activity (Table 1 , adjusted $p=0.049$, ANOVA) compared with control mice. Vertical activity here represents rearing behavior (Tatem et al., 2014). Furthermore, Btbd9 sKO mice had a significant increase in CW circling, while there was no statistical difference in CCW circling compared with control mice (Fig. 5A, CW, adjusted $p=$ 0.02 , ANOVA; CCW, adjusted $p=0.095$, ANOVA). Finally, there were no significant differences in stereotypical behavior or anxiety in the mice (Table 1). The increased activity level suggests that Btbd9 sKO mice are hyperactive. Furthermore, alterations in circling behaviors indicate imbalances in the striatal dopaminergic system (Forna- guera and Schwarting, 2002). In the long-term open field test, Btbd9 sKO mice showed no change (Fig. 5C, left panel, $p=0.35$, logistic regression with a gamma distribution) in the total distance traveled in the light phase, when mice are usually sleeping or resting. However, the sleep analysis indicates that the probability of waking of Btbd9 sKO mice significantly increased in the light phase (Fig. $5 D$, left panel, $p=0.03$, logistic regression with a binomial distribution), but did not change in the dark phase, when mice are usually active (Fig. $5 D$, right panel, $p=0.63$, logistic regression with a binomial distribution). The symptoms of RLS patients usually occur or become worse in the evening or at night (Garcia Borreguero et al., 2017). With opposite day-night rhythms to human, Btbd9 sKO mice had the motor restlessness with a similar circadian predominance as patients. In contrast, although Btbd9 ChKO mice did not show any difference in total distance traveled compared with the controls (Fig. $5 \mathrm{H}$, left panel, $p=0.28$; right panel, $p=0.16$; both logistic regression with a gamma distribution), they had a decreased probability of waking during the light phase (Fig. $5 /$, left panel, $p<0.0001$, logistic regression with a binomial distribution), especially at 1,3 , and 5 P.M. (Fig. 5/, right panel), and increased probability of waking during the dark phase (Fig. 5/, middle panel, $p=0.0029$, logistic regression with a binomial distribution), suggesting that 
A

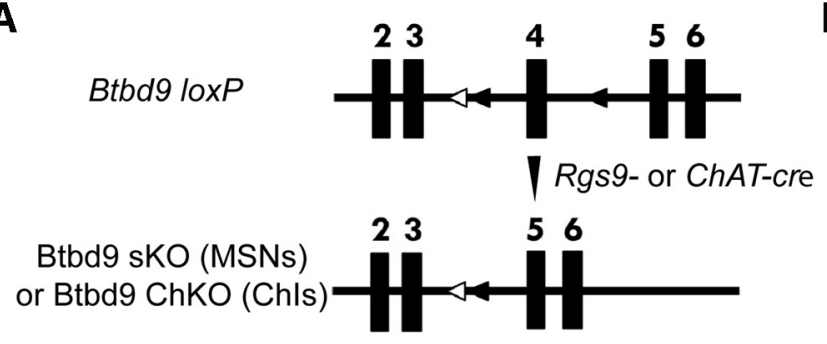

C

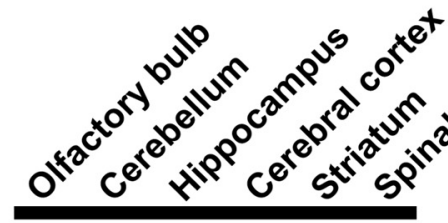

Control

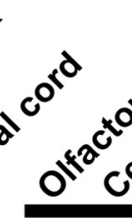

B

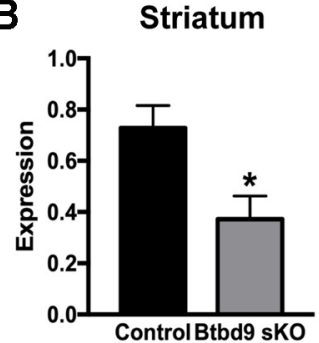

Cerebral cortex

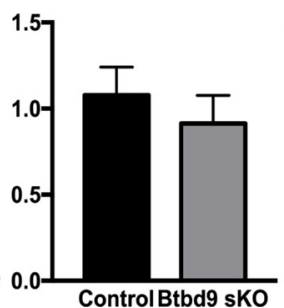

Cerebellum

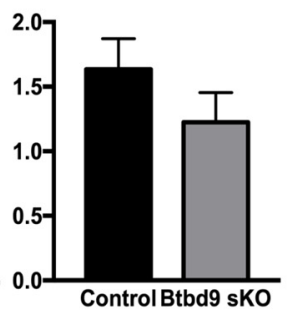

D

Figure 4. Generation of conditional KO mice and validation of the loss of Btbd9 in the striatum by qRT-PCR. $\boldsymbol{A}$, Schematic diagram of the generation of conditional KO mice. Filled boxes represent exons. Filled triangles indicate loxP sites (around the 4th exon of the $B t b d 9$ gene). Open triangles indicate the $F R T$ sites that were incorporated to remove the neo cassette. Btbd9 loxP mice were crossed with Rgs9-cre or ChAT-cre mice to obtain double heterozygotes. The double heterozygotes were crossed with Btbd9 loxP homozygotes to obtain Btbd9 sKO or Btbd9 ChKO mice. In conditional KO mice, exons 4 is deleted in specific types of neurons where cre is expressed. Recombination occurs in these cells, while other brain regions and the rest of the body still retain the intact exons. $\boldsymbol{B}, B t b d 9$ sKO mice showed a decreased level of Btbd9 mRNA in the striatum, but not in the cerebral cortex and cerebellum. Bars represent means plus SEs; $* p<0.05$. $\boldsymbol{C}$, Tissue-specific deletion of Btbd9 exon 4 in Btbd9 sKO mice was confirmed by PCR using DNA isolated from each brain region. The deletion was detected only in the striatum of Btbd9 sKO mouse as predicted $(\Delta)$. $\boldsymbol{D}$, A representative immunohistochemical image of a coronal section of the striatum from an Rgs9-cre/GFP mouse. Scale bars represent $25 \mu \mathrm{m}$. Enlarged images captured with a 40× objective lens showed that the ChAT staining (red) did not overlap with GFP staining (green). The results suggest that Rgs9-cre does not have cre-mediated recombination in Chls.

the animals sleep better than their controls. It should also be noticed that the increased probability of waking found in Btbd9 sKO mice mainly appeared during the second half of the rest phase (data not shown), which is consistence with clinical observations.

Next, we conducted a wheel running study to measure the voluntary activity of these mice under the normal 12 LD condition. Btbd9 sKO mice showed a significantly elevated level of activity compared with controls during the light and rest phase (Fig. $5 B$, light phase, $p=0.0004$, logistic regression with a negative binomial distribution), but a similar level of activity as control mice during the dark and active phase (Fig. $5 B$, dark phase, $p=0.32$, logistic regression with a negative binomial distribution). On the other hand, Btbd9 ChKO mice showed a significantly decreased activity level during the light and rest phase (Fig. 5G, left panel, $p<0.0001$, logistic regression with a negative binomial distribution) but increased activity level during the dark and active phase (Fig. 5G, right panel, $p=0.0015$, logistic regression with a negative binomial distribution). These data are consistent with the long-term open field test and suggest that only Btbd9 sKO mice have an increase in voluntary activity during their rest period. The increased voluntary activity mainly appeared during the second half of the rest phase and the first half of the active phase. Taken together, both total activity and voluntary activity were increased in the Btbd9 sKO mice in the rest phase, which resembles aspects of nocturnal RLS activity found in patients. The circadian component-involved behavior of Btbd9 ChKO mice is completely contradictory to Btbd9 sKO mice. Loss of BTBD9 protein only in MSNs, but not Chls, can cause diurnal motor restlessness in mice.

Uncomfortable sensations in lower limbs are another common phenotype of RLS (Garcia Borreguero et al., 2017). Therefore, we tested the Btbd9 sKO mice for abnormalities in the sensory system using the tail-flick test. The mutant mice had a higher level of sensitivity to the heat stimuli (Fig. $5 E, p=0.005$, logistic regression with a gamma distribution), indicating that mice lacking BTBD9 specifically in MSNs developed alterations in thermal sensation as the systematic Btbd9 $\mathrm{KO}$.

\section{Increased Chls excitability in Btbd9 ChKO mice}

The behavioral data showed that BTBD9 deficiency in MSNs, but not in Chls, can lead to RLS-like phenotypes. Therefore, it is likely that the KO of Btbd9 in Chls alone did not contribute directly to the behavioral and electrophysiological alterations observed in the systematic Btbd9 $\mathrm{KO}$ mice. To explore this, we recorded the Chls in Btbd9 


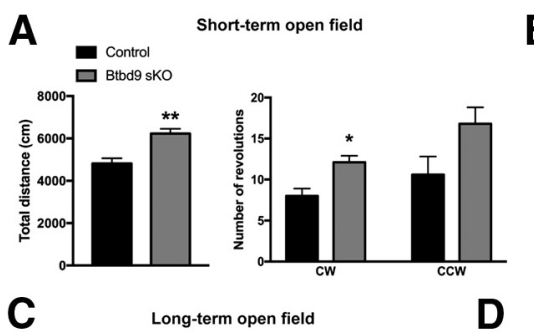

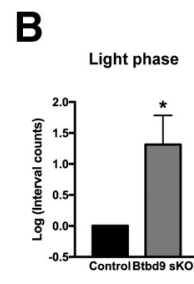

D
Light phase

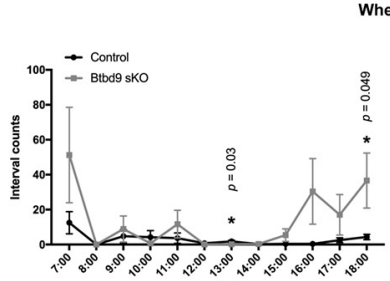

E
Wheel running

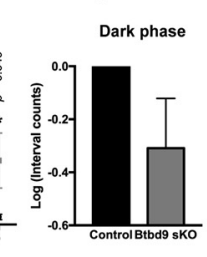

F

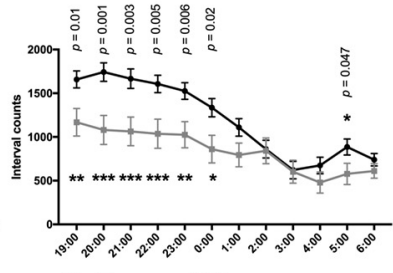

Short-term open field

Light phase Dark phase
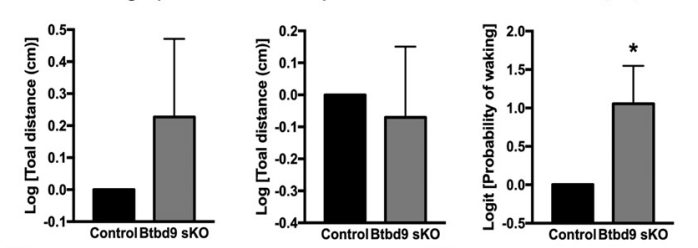

Dark phase

Tail flick
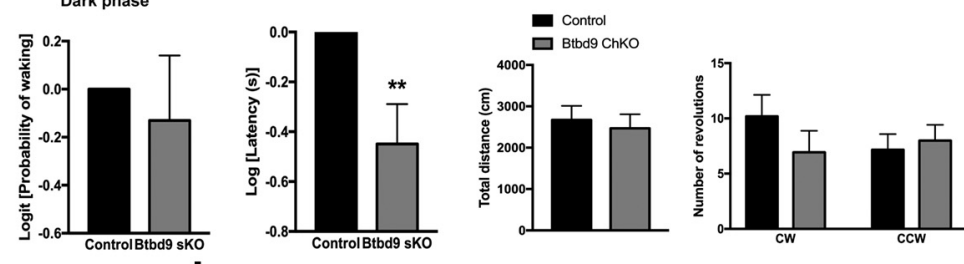

G

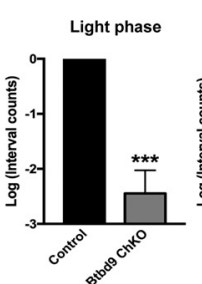

Wheel running

H

Long-term open field
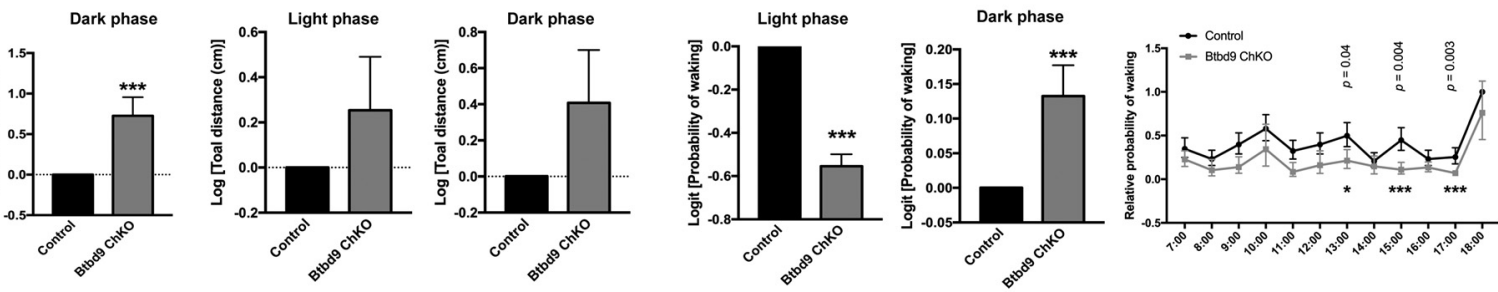

Figure 5. Behavior studies of the conditional KO mice. A, Btbd9 sKO mice traveled more and showed an increase in CW circling in the 30-min open field test. $\boldsymbol{B}, B t b d 9$ sKO mice had increased activity in the wheel running test compared with the controls during the light phase, but not in the dark phase. Detailed hourly differences are listed (see Materials and Methods). Significant $p$ values are marked above the corresponding time points. $\boldsymbol{C}$, In the long-term open field test, Btbd9 sKO mice did not show a significant change in the total distance traveled during both the light and the dark phases. $\boldsymbol{D}$, Btbd9 sKO showed an increased probability of waking in the light phase of the long-term open field test. $\boldsymbol{E}, B t b d 9$ sKO mice showed shorter latencies to respond to a warm stimulus in the tail flick test. $\boldsymbol{F}, B$ tbd9 ChKO mice did not show activity alteration in the 30-min open field test. G, Btbd9 ChKO mice ran less during the light phase but ran more during the dark phase in the wheel running test. $\boldsymbol{H}$, In the long-term open field test, Btbd9 ChKO mice did not have a significant change in the total distance traveled during both the light and the dark phases. $\boldsymbol{I}$, The probability of waking significantly decreased during the light phase and significantly increased during the dark phase for the Btbd9 ChKO mice. Detailed hourly differences are listed (see Materials and Methods). Significant $p$ values are marked above the corresponding time points. GEE model normalized the WT or control group in the bar graphs of $\boldsymbol{B}-\boldsymbol{E}, \mathbf{G}-\boldsymbol{I}$ to 0 without error bars. Bars represent means plus SEs; $* * * p<0.005, * * p<0.01, * p<0.05$.

ChKO mice for both spontaneous activity (Fig. 6C) and responses to the injected currents (Fig. 6A). We did not find the decreased activity of Chls in Btbd9 ChKO mice, as observed in the systematic Btbd9 KO (Fig. 3). Instead, spontaneous activity of Chls in the mutant mice was significantly increased (Fig. $6 D, p=0.02 ; 6 E, p=0.74$; all ANOVA), although there was no change found in intrinsic excitability (Fig. $6 B, p=0.70$, logistic regression with a negative binomial distribution). Hence, a lack of Btbd9 in Chls alone led to elevated Chl activity.

\section{Discussion}

In this study, we determined how the loss of Btbd9 affects striatal physiology and focused on the role of
MSNs in RLS pathogenesis. Using both brain imaging in vivo and electrophysiological recording in vitro, we found that the systematic Btbd9 $\mathrm{KO}$ mice had enhanced neural activity in the striatum, more excitable MSNs, and decreased activity in the Chls. In addition, specific loss of Btbd9 in the MSNs was sufficient to cause RLS-like phenotypes. When Btbd9 was conditionally knocked out in the Chls, the mice showed neither RLS-like behavioral phenotypes or maintained decreased activity in the Chls as observed with the systematic Btbd9 KO mice. The results suggest that activity changes in the Chls in the systematic Btbd9 $\mathrm{KO}$ mice are not cell-autonomous but result from alteration of striatal circuits, including changes

Table 1. Higher level of vertical activity and no alteration in anxiety or stereotypical behaviors in the open field

\begin{tabular}{lllll}
\hline \multicolumn{1}{c}{ Genotype } & Control $(n=7)$ & Btbd9 sKO $(n=8)$ & $p$ value & Adjusted $p$ value \\
Vertical activity & $410 \pm 48$ & $580 \pm 45$ & 0.026 & $0.049 *$ \\
Center time & $328 \pm 43$ & $370 \pm 41$ & 0.50 & 0.6 \\
Center distance/total distance & $0.27 \pm 0.01$ & $0.29 \pm 0.01$ & 0.43 & 0.5 \\
Stereotypy count & $2071 \pm 120$ & $2308 \pm 112$ & 0.18 & 0.3
\end{tabular}

Vertical activity is presented as the mean number of beam breaks \pm SEs. Center time is presented in seconds. Stereotypy count is presented as the number of counts; $p$ values have been adjusted for multiple comparisons using the Benjamini-Hochberg-Yekutieli FDR ( $p<0.05$ ). 
A
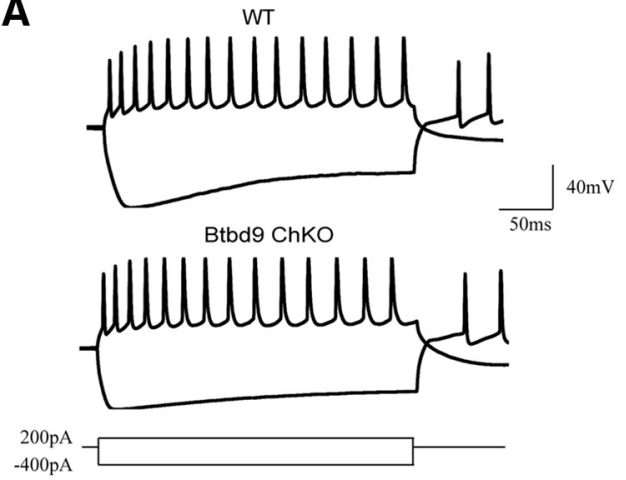

C

WT

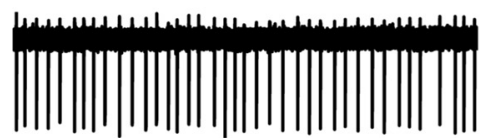

Btbd9 ChKO
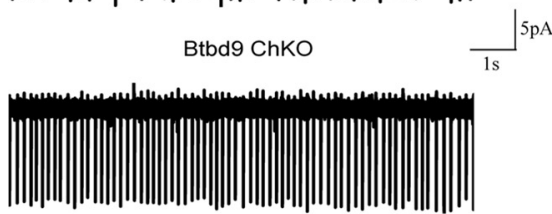

B
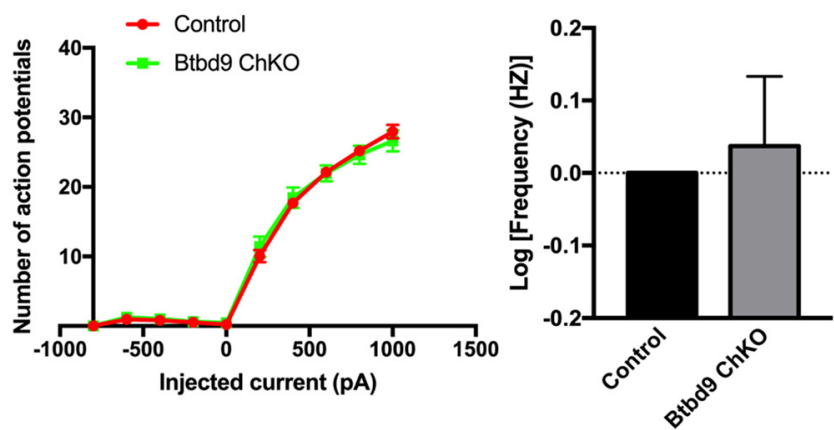

E

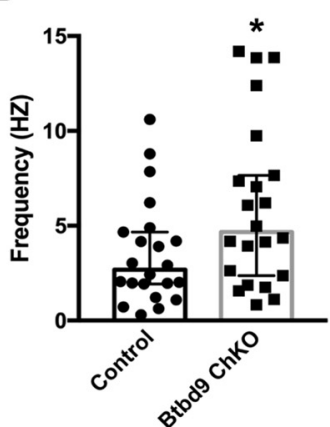

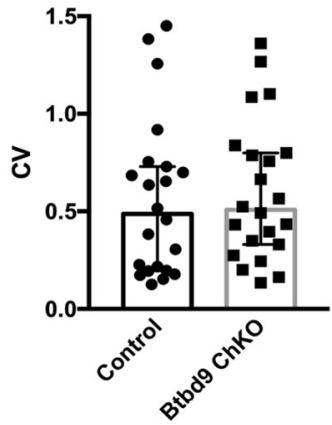

Figure 6. Electrophysiological recording of Chls from Btbd9 ChKO mice and their control littermates. $\boldsymbol{A}$, Representative responses to the injected currents at $200 \mathrm{pA}$ of ChKO ( $n=16$ cells) and control ( $n=18$ cells) mice. $\boldsymbol{B}$, The frequency-current relationship for $\mathrm{ChKO}$ and control Chls. Firing frequency of mutant Chls did not change compared with the controls. $\boldsymbol{C}$, Representative traces of spontaneous firings of mutant $(n=22)$ and control $(n=22)$ Chls. $\boldsymbol{D}$, ChKO mice had increased Chls firing frequency. $\boldsymbol{E}$, Firing regularity of Chls was not different between mutants and controls. GEE model normalized the control group in the bar graph of $\boldsymbol{B}$ to 0 without the error bars. Data in $\boldsymbol{D}$ were presented as median with $95 \% \mathrm{Cl}$. CV: coefficient of variance; $* p<0.05$.

in the MSNs. It should be noted that the current study is not aimed at generating new animal models for RLS. Instead, our findings demonstrate that striatum, especially MSNs, is critically involved in the development of RLS-like phenotypes in mice.

Our imaging study revealed increased neural activity in the systematic Btbd9 KO striatum. Close to $95 \%$ of cells in the striatum are MSNs. Therefore, the result suggests a possible overall increase in the $\mathrm{Ca}^{2+}$-dependent neural activity of MSNs. Furthermore, electrophysiological results showed an increased excitatory synaptic transmission onto striatal MSNs while their intrinsic neuronal properties were not altered. No change in the frequency, but the higher amplitude of sEPSC suggest that the MSNs of the KO mice seem to have increased excitatory synaptic inputs. Combined, our data suggest an enhancement of corticostriatal or thalamostriatal synaptic activity. Similarly, in iron deprived rat, which is thought to be an RLS rodent model, corticostriatal excitability is elevated (Yepes et al., 2017). Here, it is not known whether inputs from corticostriatal, thalamostriatal, or both contributed to the increased striatal sEPSC amplitude in the systematic Btbd9 KO mice. Differential alterations of thalamostriatal and corticostriatal synapses have been found in mouse models of Huntington's disease (Deng et al., 2014; Kolodziejczyk and Raymond, 2016; Parievsky et al., 2017), an MPTP-treated monkey model of parkinsonism (Raju et al., 2008) and a rat model with L-DOPA-induced dyskinesias (Zhang et al., 2013). Future studies will be focused on dissecting the differential effects of the systematic Btbd9 $\mathrm{KO}$ on corticostriatal and thalamostriatal synaptic transmission.

The electrophysiological recording revealed a decreased excitability in striatal Chls in the systematic Btbd9 KO mice. It has been found that Gbx2, a gene which is essential for the proper development of striatal Chls, is downed-regulated in heterozygous Meis $1 \mathrm{KO}$ embryos (E12.5; Spieler et al., 2014). MEIS1 is another gene implicated in RLS (Schormair et al., 2017). With conditional KO mice and electrophysiological recordings, we found that like Meis 1 mice, Btbd9 mutation in the Chls alone can cause functional abnormalities in striatal Chls, yet it was insufficient to produce RLS-like behaviors. In the rest phase, Btbd9 ChKO mice had decreased locomotor activity with increased excitability of striatal Chls, while the systematic Btbd9 KO mice showed increased locomotor activity (DeAndrade et al., 2012a) with decreased excitability in striatal Chls. The results suggest a critical role of Chls in movement control in the rest phase, and the decreased $\mathrm{Chl}$ activity found in the systematic Btbd9 $\mathrm{KO}$ mice is not a cell-autonomous effect. It is known that $A C h$ can regulate striatal circuit through its receptors on MSNs, GABAergic interneurons, glutamatergic and DA terminals (Lim et al., 2014). It is possible that excess release of ACh in Btbd9 ChKO mice downregulated activities of MSNs directly through the nAChRs (Liu 
et al., 2007) and M4 receptors (Howe and Surmeier, 1995) or indirectly by increasing GABAergic inhibition on MSNs (English et al., 2011). As the sole output of the striatum, MSNs may lead to decreased locomotion through their decreased activities. However, when Btbd9 was knocked out systematically, neuronal activities were changed in both MSNs and Chls. Our results showed that MSNs became more excitable and may have increased activity. These changes in MSNs were likely to be dominant and overcame the influence of Chls. MSNs, via their inhibition on the Chls, in turn, led to decreased activity in Chls as showed by the electrophysiological recording. Although it is not clear if the activity level of MSNs in the Btbd9 sKO mice is the same as what we found in the systematic Btbd9 KO, Btbd9 sKO mice did show an opposite output in behavioral tests as Btbd9 ChKOs, which support the overwhelmingly inhibitory effect of MSNs to Chls as mentioned above.

MSNs-specific Btbd9 KO was found to be sufficient to induce rest-phase specific hyperactive movement, sleep disturbance, and increased thermal sensation in mice. The findings support the idea that striatum is critical for the pathogenesis of RLS motor phenotypes. Postmortem studies comparing RLS patients and control group show a decreased $D_{2} R$ expression in the putamen, but increased phosphorylated tyrosine hydroxylase $(\mathrm{TH})$, a ratelimiting enzyme for DA synthesis, in both putamen and SN (Connor et al., 2009). Brain imaging studies indicate decreased membrane-bound DAT level and $D_{2} R$ binding potential in the striatum (Rizzo et al., 2017). Additionally, changes in iron hemostasis have been found in $\mathrm{SN}$ and putamen of RLS patients (Allen et al., 2001; Earley et al., 2014). Striata of iron-deprived RLS rodent models show a reduced density of DAT and DA receptors (Erikson et al., $2000,2001)$ and enhanced release at corticostriatal terminals (Yepes et al., 2017). Taken together, these studies suggest functional alterations in the striatum are correlated with RLS (Rizzo et al., 2017). In addition, a recent GWAS study demonstrated that striatal MSNs are associated with insomnia (Jansen et al., 2019), which can be caused by RLS.

However, dysfunctional striatal circuit caused by the loss of BTBD9 might not be the only mechanism in the systematic $B t b d 9 \mathrm{KO}$ mice. Btbd9 is also expressed in the spinal cord, although our genomic PCR failed to detect any deletion of the Btbd9 gene in the spinal cord of the Btbd9 sKO mice. Alterations in the striatum can lead to alterations in the spinal cord. The basal ganglia output modulates the spinal cord through feedback to the cortex. Additionally, recent evidence has suggested that a microcircuit exists between the corticostriatal tract and the corticospinal tract, starting in the striatum and ending in the spinal cord (Kiritani et al., 2012). Spinal neural circuits have been proposed to be central in RLS development (Clemens et al., 2006; Zwartbol et al., 2013; Koblinger et al., 2014; Kumru et al., 2015). It has been found that a lesion in a dorsoposterior hypothalamic dopaminergic A11 cell group, which is the sole source of spinal DA, leads to increased wakefulness across the rest phase (Ondo et al., 2000) and a long-lasting reduction in sensory thresholds (Clemens et al., 2006) in rats. $D_{3}$ receptors are mostly present in the dorsal spinal cord where it has been shown to modulate sensory pathways (Meneely et al., 2018). Mice knocked out of $D_{3}$ receptors $\left(D_{3} K O\right)$ show increased locomotion (Accili et al., 1996; Clemens et al., 2006) and decreased paw withdrawal latencies to thermal pain stimulation. Furthermore, $\mathrm{D}_{3} \mathrm{KO}$ mice have a reduction in frequency-dependent modulation of the longerlatency reflex (LLRs) in the spinal cord (Keeler et al., 2012). Pharmacological experiments indicate that $D_{3} K O$ mice exhibit a reversal of the modulatory actions of DA on spinal reflexes from depression to facilitation (Clemens and Hochman, 2004), and are responsive to $D_{1}$ and $D_{2}$ receptor agonists (Keeler et al., 2012). These findings emphasize the role of spinal DA in the etiology of RLS.

Our results provide a novel mechanism for the efficacy of dopaminergic agonists as treatments for RLS. The dopaminergic system plays a critical role in RLS pathogenesis. In addition to the evidence mentioned above, RLS patients have upregulated levels of L-DOPA metabolites and TH activity in CSF (Earley et al., 2001; Allen et al., 2009). RNAi-mediated knock-down of BTBD9 homolog gene in a subset of dopaminergic neurons can reproduce sleep phenotype in fruit flies (Freeman et al., 2012). Ropinirole rescues the sensory deficit found in the systematic Btbd9 KO mice (DeAndrade et al., 2012a). It is possible that increased activity of MSNs leads to a decreased firing in the Chls and a lower level of ACh. Nigrostriatal DA terminals express both ionotropic nicotinic ACh (nACh) and $\mathrm{G}_{\mathrm{q} / 11}$-coupled muscarinic ACh (mACh) receptors (Cachope and Cheer, 2014). The activation of nACh receptors elicits DA release, while the downstream pathway of mACh receptor inhibits DA release. Overall, optogenetic stimulation of Chls evokes DA release in slice preparation (Cachope et al., 2012; Cachope and Cheer, 2014). Therefore, a decreased level of ACh may cause a deficiency in DA release. It has also been found that activation of MSNs through AMPA receptor leads to the generation of a diffusible messenger, hydrogen peroxide $\left(\mathrm{H}_{2} \mathrm{O}_{2}\right)$, which can inhibit DA release via ATP-sensitive potassium channels (Avshalumov et al., 2008; Sulzer et al., 2017). Either way, increased MSNs activity is predicted to reduce striatal DA release in the systematic Btbd9 KO mouse model, which is consistent with the clinical finding that DA agonists can be used to treat RLS.

In summary, our results suggest that alteration in the striatal circuit, especially increased activity of the striatal MSNs, could potentially serve as a main pathogenetic mechanism of the motor and sensory dysfunction in RLS. It also supports an indirect role of the striatal Chls in the disease development. Finally, these data present a plausible explanation for the therapeutic efficacy of the DA receptor agonists in RLS that includes the inhibition of the MSNs activity, the regulation of $\mathrm{Chl}$ excitability, and the resetting of the striatal circuit. Further investigations are needed to dissect the complex interactions among the striatal neurons and modulatory neurotransmitters, which will aid the development of highly selective anti-RLS drugs with fewer side effects. 


\section{References}

Accili D, Fishburn CS, Drago J, Steiner H, Lachowicz JE, Park BH, Gauda EB, Lee EJ, Cool MH, Sibley DR, Gerfen CR, Westphal H, Fuchs S (1996) A targeted mutation of the D3 dopamine receptor gene is associated with hyperactivity in mice. Proc Natl Acad Sci USA 93:1945-1949.

Allen RP, Barker PB, Wehrl FW, Song HK, Earley CJ (2001) MRI measurement of brain iron in patients with restless legs syndrome. Neurology 56:263-265.

Allen RP, Connor JR, Hyland K, Earley CJ (2009) Abnormally increased CSF 3-Ortho-methyldopa (3-OMD) in untreated restless legs syndrome (RLS) patients indicates more severe disease and possibly abnormally increased dopamine synthesis. Sleep Med 10:123-128.

Allen RP, Donelson NC, Jones BC, Li Y, Manconi M, Rye DB, Sanyal S, Winkelmann J (2017) Animal models of RLS phenotypes. Sleep Med 31:23-28.

Augustin SM, Chancey JH, Lovinger DM (2018) Dual dopaminergic regulation of corticostriatal plasticity by cholinergic interneurons and indirect pathway medium spiny neurons. Cell Rep 24:28832893.

Avshalumov MV, Patel JC, Rice ME (2008) AMPA receptordependent $\mathrm{H} 2 \mathrm{O} 2$ generation in striatal medium spiny neurons but not dopamine axons: one source of a retrograde signal that can inhibit dopamine release. J Neurophysiol 100:1590-1601.

Bohnen NI, Albin RL (2011) The cholinergic system and Parkinson disease. Behav Brain Res 221:564-573.

Bordia T, Perez XA, Heiss J, Zhang D, Quik M (2016) Optogenetic activation of striatal cholinergic interneurons regulates L-dopainduced dyskinesias. Neurobiol Dis 91:47-58.

Cachope R, Cheer JF (2014) Local control of striatal dopamine release. Front Behav Neurosci 8:188.

Cachope R, Mateo Y, Mathur BN, Irving J, Wang HL, Morales M, Lovinger DM, Cheer JF (2012) Selective activation of cholinergic interneurons enhances accumbal phasic dopamine release: setting the tone for reward processing. Cell Rep 2:33-41.

Chiu CH, Siow TY, Weng SJ, Hsu YH, Huang YS, Chang KW, Cheng CY, Ma KH (2015) Effect of MDMA-induced axotomy on the dorsal raphe forebrain tract in rats: an in vivo manganese-enhanced magnetic resonance imaging study. PLoS One 10:e0138431.

Clemens S, Hochman S (2004) Conversion of the modulatory actions of dopamine on spinal reflexes from depression to facilitation in D3 receptor knock-out mice. J Neurosci 24:11337-11345.

Clemens S, Rye D, Hochman S (2006) Restless legs syndrome: revisiting the dopamine hypothesis from the spinal cord perspective. Neurology 67:125-130.

Connor JR, Patton S, Oexle K, Allen R (2017) Iron and restless legs syndrome: treatment, genetics and pathophysiology. Sleep Med $31: 61-70$.

Connor JR, Wang XS, Allen RP, Beard JL, Wiesinger JA, Felt BT, Earley CJ (2009) Altered dopaminergic profile in the putamen and substantia nigra in restless leg syndrome. Brain 132:2403-2412.

Cox J, Witten IB (2019) Striatal circuits for reward learning and decision-making. Nat Rev Neurosci 20:482-494.

Dang MT, Yokoi F, Yin HH, Lovinger DM, Wang Y, Li Y (2006) Disrupted motor learning and long-term synaptic plasticity in mice lacking NMDAR1 in the striatum. Proc Natl Acad Sci USA 103: 15254-15259.

Dang MT, Yokoi F, Cheetham CC, Lu J, Vo V, Lovinger DM, Li Y (2012) An anticholinergic reverses motor control and corticostriatal LTD deficits in Dyt1 $\triangle$ GAG knock-in mice. Behav Brain Res 226: 465-472.

DeAndrade MP, Johnson RL Jr, Unger EL, Zhang L, van Groen T, Gamble KL, Li Y (2012a) Motor restlessness, sleep disturbances, thermal sensory alterations and elevated serum iron levels in Btbd9 mutant mice. Hum Mol Genet 21:3984-3992.

DeAndrade MP, Zhang L, Doroodchi A, Yokoi F, Cheetham CC, Chen HX, Roper SN, Sweatt JD, Li Y (2012b) Enhanced hippocam- pal long-term potentiation and fear memory in Btbd9 mutant mice. PLoS One 7:e35518.

Deng YP, Wong T, Wan JY, Reiner A (2014) Differential loss of thalamostriatal and corticostriatal input to striatal projection neuron types prior to overt motor symptoms in the Q140 knock-in mouse model of Huntington's disease. Front Syst Neurosci 8:198.

Dudek M, Abo-Ramadan U, Hermann D, Brown M, Canals S, Sommer WH, Hyytiä P (2015) Brain activation induced by voluntary alcohol and saccharin drinking in rats assessed with manganeseenhanced magnetic resonance imaging. Addict Biol 20:10121021.

Duong TQ, Silva AC, Lee SP, Kim SG (2000) Functional MRI of calcium-dependent synaptic activity: cross correlation with CBF and BOLD measurements. Magn Reson Med 43:383-392.

Earley CJ, Hyland K, Allen RP (2001) CSF dopamine, serotonin, and biopterin metabolites in patients with restless legs syndrome. Mov Disord 16:144-149.

Earley CJ, Kuwabara H, Wong DF, Gamaldo C, Salas R, Brasic J, Ravert HT, Dannals RF, Allen RP (2011) The dopamine transporter is decreased in the striatum of subjects with restless legs syndrome. Sleep 34:341-347.

Earley CJ, Kuwabara H, Wong DF, Gamaldo C, Salas RE, Brašić JR, Ravert HT, Dannals RF, Allen RP (2013) Increased synaptic dopamine in the putamen in restless legs syndrome. Sleep 36:51-57.

Earley CJ, Connor J, Garcia-Borreguero D, Jenner P, Winkelman J, Zee PC, Allen R (2014) Altered brain iron homeostasis and dopaminergic function in restless legs syndrome (Willis-Ekbom disease). Sleep Med 15:1288-1301.

Earley CJ, Uhl GR, Clemens S, Ferré S (2017) Connectome and molecular pharmacological differences in the dopaminergic system in restless legs syndrome (RLS): plastic changes and neuroadaptations that may contribute to augmentation. Sleep Med 31: 71-77.

English DF, Ibanez-Sandoval O, Stark E, Tecuapetla F, Buzsáki G, Deisseroth K, Tepper JM, Koos T (2011) GABAergic circuits mediate the reinforcement-related signals of striatal cholinergic interneurons. Nat Neurosci 15:123-130.

Erikson KM, Jones BC, Beard JL (2000) Iron deficiency alters dopamine transporter functioning in rat striatum. J Nutr 130:2831-2837.

Erikson KM, Jones BC, Hess EJ, Zhang Q, Beard JL (2001) Iron deficiency decreases dopamine $\mathrm{D} 1$ and $\mathrm{D} 2$ receptors in rat brain. Pharmacol Biochem Behav 69:409-418.

Eskow Jaunarajs KL, Bonsi P, Chesselet MF, Standaert DG, Pisani A (2015) Striatal cholinergic dysfunction as a unifying theme in the pathophysiology of dystonia. Prog Neurobiol 127-128:91-107.

Ferré S, García-Borreguero D, Allen RP, Earley CJ (2019) New insights into the neurobiology of restless legs syndrome. Neuroscientist 25:113-125

Fornaguera J, Schwarting RK (2002) Time course of deficits in open field behavior after unilateral neostriatal 6-hydroxydopamine lesions. Neurotox Res 4:41-49.

Freeman A, Pranski E, Miller RD, Radmard S, Bernhard D, Jinnah HA Betarbet R, Rye DB, Sanyal S (2012) Sleep fragmentation and motor restlessness in a Drosophila model of restless legs syndrome. Curr Biol 22:1142-1148.

Fukuda J, Kawa K (1977) Permeation of manganese, cadmium, zinc, and beryllium through calcium channels of an insect muscle membrane. Science 196:309-311.

Garcia-Borreguero D, Cano-Pumarega I (2017) New concepts in the management of restless legs syndrome. BMJ 356:j104.

Garcia Borreguero D, Winkelmann J, Allen RP (2017) Introduction: towards a better understanding of the science of RLS/WED. Sleep Med 31:1-2.

Haber SN (2016) Corticostriatal circuitry. Dialogues Clin Neurosci 18:7-21.

Howe AR, Surmeier DJ (1995) Muscarinic receptors modulate N-, P-, and L-type $\mathrm{Ca} 2+$ currents in rat striatal neurons through parallel pathways. J Neurosci 15:458-469.

Hsu YH, Chen CC, Zechariah A, Yen CC, Yang LC, Chang C (2008) Neuronal dysfunction of a long projecting multisynaptic pathway in 
response to methamphetamine using manganese-enhanced MRI. Psychopharmacology (Berl) 196:543-553.

Jansen PR, Watanabe K, Stringer S, Skene N, Bryois J, Hammerschlag AR, de Leeuw CA, Benjamins JS, Muñoz-Manchado AB, Nagel M, Savage JE, Tiemeier H, White T, 23andMe Research Team, Tung JY, Hinds DA, Vacic V, Wang X, Sullivan PF, van der Sluis S, et al. (2019) Genome-wide analysis of insomnia in $1,331,010$ individuals identifies new risk loci and functional pathways. Nat Genet 51:394-403.

Jenkinson M, Beckmann CF, Behrens TE, Woolrich MW, Smith SM (2012) FSL. Neuroimage 62:782-790.

Jiménez-Jiménez FJ, Alonso-Navarro H, García-Martín E, Agúndez JAG (2018) Genetics of restless legs syndrome: an update. Sleep Med Rev 39:108-121.

Keeler BE, Baran CA, Brewer KL, Clemens S (2012) Increased excitability of spinal pain reflexes and altered frequency-dependent modulation in the dopamine D3-receptor knockout mouse. Exp Neurol 238:273-283.

Kiritani T, Wickersham IR, Seung HS, Shepherd GM (2012) Hierarchical connectivity and connection-specific dynamics in the corticospinal-corticostriatal microcircuit in mouse motor cortex. J Neurosci 32:4992-5001.

Koblinger K, Füzesi T, Ejdrygiewicz J, Krajacic A, Bains JS, Whelan PJ (2014) Characterization of A11 neurons projecting to the spinal cord of mice. PLoS One 9:e109636.

Kolodziejczyk K, Raymond LA (2016) Differential changes in thalamic and cortical excitatory synapses onto striatal spiny projection neurons in a Huntington disease mouse model. Neurobiol Dis 86:62-74

Kumru H, Vidal J, Benito J, Barrio M, Portell E, Valles M, Flores C, Santamaria J (2015) Restless leg syndrome in patients with spinal cord injury. Parkinsonism Relat Disord 21:1461-1464.

Lanza G, Ferri R (2019) The neurophysiology of hyperarousal in restless legs syndrome: hints for a role of glutamate/GABA. Adv Pharmacol 84:101-119.

Lanza G, Bachmann CG, Ghorayeb I, Wang Y, Ferri R, Paulus W (2017) Central and peripheral nervous system excitability in restless legs syndrome. Sleep Med 31:49-60.

Lim SA, Kang UJ, McGehee DS (2014) Striatal cholinergic interneuron regulation and circuit effects. Front Synaptic Neurosci 6:22.

Liu Z, Otsu Y, Vasuta C, Nawa H, Murphy TH (2007) Action-potentialindependent GABAergic tone mediated by nicotinic stimulation of immature striatal miniature synaptic transmission. J Neurophysiol 98:581-593.

Lu H, Xi ZX, Gitajn L, Rea W, Yang Y, Stein EA (2007) Cocaineinduced brain activation detected by dynamic manganeseenhanced magnetic resonance imaging (MEMRI). Proc Natl Acad Sci USA 104:2489-2494.

Meneely S, Dinkins M-L, Kassai M, Lyu S, Liu Y, Lin C-T, Brewer K, Li Y, Clemens S (2018) Differential dopamine D1 and D3 receptor modulation and expression in the spinal cord of two mouse models of restless legs syndrome. Front Behav Neurosci 12:199.

Michaud M, Soucy JP, Chabli A, Lavigne G, Montplaisir J (2002) SPECT imaging of striatal pre- and postsynaptic dopaminergic status in restless legs syndrome with periodic leg movements in sleep. J Neurol 249:164-170.

Murayama Y, Weber B, Saleem KS, Augath M, Logothetis NK (2006) Tracing neural circuits in vivo with Mn-enhanced MRI. Magn Reson Imaging 24:349-358.

Narita K, Kawasaki F, Kita H (1990) Mn and Mg influxes through Ca channels of motor nerve terminals are prevented by verapamil in frogs. Brain Res 510:289-295.

Ondo WG, He Y, Rajasekaran S, Le WD (2000) Clinical correlates of 6-hydroxydopamine injections into A11 dopaminergic neurons in rats: a possible model for restless legs syndrome. Mov Disord 15:154-158.

Pappas SS, Darr K, Holley SM, Cepeda C, Mabrouk OS, Wong JM, LeWitt TM, Paudel R, Houlden H, Kennedy RT, Levine MS, Dauer WT (2015) Forebrain deletion of the dystonia protein torsinA causes dystonic-like movements and loss of striatal cholinergic neurons. Elife 4:e08352.

Parievsky A, Moore C, Kamdjou T, Cepeda C, Meshul CK, Levine MS (2017) Differential electrophysiological and morphological alterations of thalamostriatal and corticostriatal projections in the R6/2 mouse model of Huntington's disease. Neurobiol Dis 108:29-44.

Pautler RG, Silva AC, Koretsky AP (1998) In vivo neuronal tract tracing using manganese-enhanced magnetic resonance imaging. Magn Reson Med 40:740-748.

Perez PD, Hall G, Kimura T, Ren Y, Bailey RM, Lewis J, Febo M, Sahara N (2013) In vivo functional brain mapping in a conditional mouse model of human tauopathy (tauP301L) reveals reduced neural activity in memory formation structures. Mol Neurodegener 8:9.

Perez PD, Hall G, Zubcevic J, Febo M (2018) Cocaine differentially affects synaptic activity in memory and midbrain areas of female and male rats: an in vivo MEMRI study. Brain Imaging Behav 12:201-216.

Perrine SA, Ghoddoussi F, Desai K, Kohler RJ, Eapen AT, Lisieski MJ, Angoa-Perez M, Kuhn DM, Bosse KE, Conti AC, Bissig D, Berkowitz BA (2015) Cocaine-induced locomotor sensitization in rats correlates with nucleus accumbens activity on manganeseenhanced MRI. NMR Biomed 28:1480-1488.

Purves D, Augustine GJ, Fitzpatrick D, Katz LC, LaMantia AS, McNamara JO, Williams SM (2001a) Projections to the basal ganglia. Sunderland, MA: Sinauer Associates.

Purves D, Augustine GJ, Fitzpatrick D, Katz LC, LaMantia AS, McNamara JO, Williams SM (2001b) Circuits within the basal ganglia system. Sunderland, MA: Sinauer Associates.

Raju DV, Ahern TH, Shah DJ, Wright TM, Standaert DG, Hall RA, Smith Y (2008) Differential synaptic plasticity of the corticostriatal and thalamostriatal systems in an MPTP-treated monkey model of parkinsonism. Eur J Neurosci 27:1647-1658.

Rizzo G, Li X, Galantucci S, Filippi M, Cho YW (2017) Brain imaging and networks in restless legs syndrome. Sleep Med 31:39-48.

Saleem KS, Pauls JM, Augath M, Trinath T, Prause BA, Hashikawa T, Logothetis NK (2002) Magnetic resonance imaging of neuronal connections in the macaque monkey. Neuron 34:685-700.

Schormair B, Zhao C, Bell S, Tilch E, Salminen AV, Pütz B, Dauvilliers Y, Stefani A, Högl B, Poewe W, Kemlink D, Sonka K, Bachmann CG, Paulus W, Trenkwalder C, Oertel WH, Hornyak M, TederLaving M, Metspalu A, Hadjigeorgiou GM, et al. (2017) Identification of novel risk loci for restless legs syndrome in genome-wide association studies in individuals of European ancestry: a metaanalysis. Lancet Neurol 16:898-907.

Silber MH, Becker PM, Buchfuhrer MJ, Earley CJ, Ondo WG, Walters AS, Winkelman JW (2018) The appropriate use of opioids in the treatment of refractory restless legs syndrome. Mayo Clin Proc 93:59-67.

Sloot WN, Gramsbergen JB (1994) Axonal transport of manganese and its relevance to selective neurotoxicity in the rat basal ganglia. Brain Res 657:124-132.

Soares-Cunha C, Coimbra B, Sousa N, Rodrigues AJ (2016) Reappraising striatal D1- and D2-neurons in reward and aversion. Neurosci Biobehav Rev 68:370-386.

Spieler D, Kaffe M, Knauf F, Bessa J, Tena JJ, Giesert F, Schormair B, Tilch E, Lee H, Horsch M, Czamara D, Karbalai N, von Toerne C, Waldenberger M, Gieger C, Lichtner P, Claussnitzer M, Naumann R, Müller-Myhsok B, Torres M, et al. (2014) Restless legs syndrome-associated intronic common variant in Meis1 alters enhancer function in the developing telencephalon. Genome Res 24:592-603.

Spijker S (2011) Dissection of rodent brain regions. Neuroproteomics 57:13-26.

Stogios PJ, Privé GG (2004) The BACK domain in BTB-kelch proteins. Trends Biochem Sci 29:634-637.

Stogios PJ, Downs GS, Jauhal JJ, Nandra SK, Privé GG (2005) Sequence and structural analysis of BTB domain proteins. Genome Biol 6:R82. 
Sulzer D, Cragg SJ, Rice ME (2017) Chapter 19 - Regulation of extracellular dopamine: release and uptake. In: Handbook of behavioral neuroscience (Steiner H, Tseng KY, eds), pp 373-402. Amsterdam: Elsevier.

Takeda A, Ishiwatari S, Okada S (1998a) In vivo stimulationinduced release of manganese in rat amygdala. Brain Res 811: 147-151.

Takeda A, Kodama Y, Ishiwatari S, Okada S (1998b) Manganese transport in the neural circuit of rat CNS. Brain Res Bull 45:149-152.

Tatem KS, Quinn JL, Phadke A, Yu Q, Gordish-Dressman H, Nagaraju K (2014) Behavioral and locomotor measurements using an open field activity monitoring system for skeletal muscle diseases. J Vis $\operatorname{Exp}(91): 51785$.

Trenkwalder C, Allen R, Högl B, Clemens S, Patton S, Schormair B, Winkelmann J (2018) Comorbidities, treatment, and pathophysiology in restless legs syndrome. Lancet Neurol 17:994-1005.

Yepes G, Guitart X, Rea W, Newman AH, Allen RP, Earley CJ, Quiroz C, Ferré S (2017) Targeting hypersensitive corticostriatal terminals in restless legs syndrome. Ann Neurol 82:951-960.
Yokoi F, Dang MT, Li J, Standaert DG, Li Y (2011) Motor deficits and decreased striatal dopamine receptor 2 binding activity in the striatum-specific Dyt1 conditional knockout mice. PLoS One 6:e24539.

Zhang Y, Meredith GE, Mendoza-Elias N, Rademacher DJ, Tseng KY, Steece-Collier K (2013) Aberrant restoration of spines and their synapses in I-DOPA-induced dyskinesia: involvement of corticostriatal but not thalamostriatal synapses. J Neurosci 33:11655-11667.

Zubcevic J, Watkins J, Perez PD, Colon-Perez LM, Long MT, Febo $M$, Hayward L (2018) MEMRI reveals altered activity in brain regions associated with anxiety, locomotion, and cardiovascular reactivity on the elevated plus maze in the WKY vs SHR rats. Brain Imaging Behav 12:1318-1331.

Zucca S, Zucca A, Nakano T, Aoki S, Wickens J (2018) Pauses in cholinergic interneuron firing exert an inhibitory control on striatal output in vivo. Elife 7:e32510.

Zwartbol RT, Jellema K, Boiten J, Rijsman R (2013) Acute exacerbation of restless legs due to cervical spinal cord ischaemia. BMJ Case Rep 2013:bcr2012007930. 